\title{
Tuning the surface properties of biochar by thermal treatment
}

\author{
Fernanda Gomes de Mendonça ${ }^{\mathrm{a}}$, Igor Tadeu da Cunha ${ }^{\mathrm{a}}$, Ricardo Reis Soares ${ }^{\mathrm{b}}$, \\ Juliana Cristina Tristão ${ }^{c}$, Rochel Montero Lago ${ }^{\mathrm{a}, *}$ \\ a Departamento de Química, Universidade Federal de Minas Gerais, Belo Horizonte, MG 31270-901, Brazil \\ b Faculdade de Engenharia Química, Universidade Federal de Uberlândia, Uberlândia 38408-100, Brazil \\ c Universidade Federal de Viçosa - Campus de Florestal. Rodovia LMG, 818-km 6, Florestal, MG 35690-000, Brazil
}

\section{A R T I C L E I N F O}

\section{Keywords:}

Biochar

Thermal treatment

Graphene

Dye adsorption

Sulfide oxidation

\begin{abstract}
A B S T R A C T
In this work, the effect of controlled thermal treatment to tune biochar surface properties such as area/porosity, functionalities and reactivity was investigated. TG-MS, CHN, Raman, IR, BET, Zeta and SEM analyses suggested that thermal treatment led to the decomposition of an organic complex/amorphous phase to produce micropores based on graphene nanostructures and a strong increase on surface area from $3 \mathrm{~m}^{2} \mathrm{~g}^{-1}$ for biochar to 30,408 and $590 \mathrm{~m}^{2} \mathrm{~g}^{-1}$, at 400,600 and $800{ }^{\circ} \mathrm{C}$, respectively. The treatment also led to a gradual decrease on oxygen content from 27 to $14 \mathrm{wt} \%$ at $800{ }^{\circ} \mathrm{C}$ due to decomposition of surface functionalities changing surface properties such as zeta potential, adsorption of anionic and cationic species and an increase on the activity for sulfide oxidation which is discussed in terms of increase in surface area and the presence of surface redox quinone groups.
\end{abstract}

\section{Introduction}

The production of bio-oil by flash pyrolysis is considered a promising route to convert biomass wastes into fuel and feedstocks for biorefineries processes (Bridgwater, 2012). Biochar is the solid product of biomass flash pyrolysis with a composition based mainly on carbon, hydrogen, oxygen and metals, e.g. Ca, K and Mg (Stutter, 2015; Yargicoglu et al., 2015). Biochars obtained from lignocellulosic biomass contains mainly oxygenated functional groups which are responsible for a rich and complex surface chemistry (Chintala et al., 2014; Huang et al., 2016). The number and nature of these surface oxygen functionalities varies according to the pyrolysis temperature (Huang et al., 2016; Kim et al., 2011; Mukherjee et al., 2011; Usman et al., 2015).

The main applications of biochar explored in literature are related to the direct use in agriculture for soil amendment (Beesley et al., 2011; Brennan et al., 2014; Kim et al., 2014; Schmidt et al., 2014; Zhao et al., 2016). More recently, the use of biochar in environmental applications has been investigated, e.g. as adsorbent for heavy metal ions (Ding et al., 2016; Jin et al., 2016; Liu et al., 2016; Qian et al., 2016), phosphate and ammonium (Takaya et al., 2016) and pharmaceutical compounds (Shan et al., 2016). However, all these applications as adsorbent are strongly limited due to the very low surface area and porosity (Lee et al., 2010).

Sulfides from wastewater are toxic to aquatic ecosystems and corrosive even at very low concentrations (Burgess et al., 2001). Thus, the need of efficient and low cost technologies to remove sulfide from aqueous phase is of considerable interest. Different removal methods have been investigated in the last years, including biooxidation on microbial biofilms (Tang et al., 2010), electrocatalytic oxidation on modified electrodes (Dilgin et al., 2012) and adsorption on modified activated carbon (Ben Hariz et al., 2014). Recently, three sulfide oxidation catalyst families have been developed for aqueous medium, i.e. ferrites (Cunha et al., 2016a,b), functionalized carbons (Lemos et al., 2012; Lemos et al., 2013) and ferrite/carbon composites (Cunha et al., 2016a,b). The basic common features of these catalysts are surface redox functionalities and electron conducting structures. In the case of the carbon catalysts, these previous works suggest that redox oxygen surface groups play a key role on the reaction with sulfide to remove an electron, which will be dispersed by the electric conducting graphene structures. As biochars contain different oxygenated functional groups such as hydroxyl, carboxyl and carbonyl (Ahmed et al., 2016; Li et al., 2013), they can be potentially active for sulfide oxidation. One of the aims of this work was to investigate the effect of thermal treatment on the presence of biochar's oxygen groups and other factors, such as surface area and carbon structure, which can affect sulfide oxidation.

In this work, a systematic study on the effect of thermal treatment on oxygen functionalities and surface area of a biochar was carried out. The treated biochars were preliminarily used for the adsorption of model dye molecules, i.e. cationic methylene blue and anionic indigo carmine, and as catalyst for sulfide oxidation in aqueous medium.

\footnotetext{
* Corresponding author.

E-mail address: rochel@ufmg.br (R.M. Lago).
} 


\section{Experimental}

Biochar was formed during the production of bio-oil from fast pyrolysis of a mixture of sawdust and sugarcane straw, performed in a pilot plant. This biochar was pre-treated with concentrated $\mathrm{HCl}$ under reflux for $12 \mathrm{~h}$ to remove soluble metals. It was extensively washed with a solution of $\mathrm{NaOH} 1 \mathrm{~mol} \mathrm{~L}^{-1}$, a solution of $\mathrm{NaHCO}_{3} 1 \mathrm{~mol} \mathrm{~L}^{-1}$ and distilled water, until the washing water reached $\mathrm{pH}$ 6. The material was dried in oven at $80{ }^{\circ} \mathrm{C}$ overnight and it was denominated $\mathrm{B}$.

\subsection{Thermal treatment of biochar}

Thermal treatment at different temperatures, 400, 600 and $800{ }^{\circ} \mathrm{C}$, was carried out with $3 \mathrm{~g}$ of $\mathrm{B}$ in a flux of $\mathrm{N}_{2}\left(50 \mathrm{~mL} \mathrm{~min}^{-1}\right)$, in a quartz tube into a horizontal furnace (BLUE M. Lindberg) at a heating rate of $10{ }^{\circ} \mathrm{C} \mathrm{min}{ }^{-1}$, maintaining the final temperature for an hour. Three materials were prepared, besides B, named B400, B600 and B800.

\subsection{Characterization}

Thermogravimetric analyses (TG) were carried out in a Shimadzu TGA-60, with a constant heating rate of $10{ }^{\circ} \mathrm{C} \mathrm{min}^{-1}$ under air or $\mathrm{N}_{2}$ dynamic flow $\left(50 \mathrm{~mL} \mathrm{~min}^{-1}\right)$. Thermogravimetric-mass spectrometry (TG-MS) analyses were performed in a NETZSCH equipment model STA 449 F3, coupled to a mass spectrometer NETZSCH Aëolos model QMS $403 \mathrm{C}$. It was used about $20 \mathrm{mg}$ of sample under an argon flow in the purge and protective lines, both at $20 \mathrm{~mL} \mathrm{~min}{ }^{-1}$. The heating rate was up to $900{ }^{\circ} \mathrm{C}$ at $5{ }^{\circ} \mathrm{C} \mathrm{min}^{-1}$. Infrared spectroscopy (IR) was performed in a Perkin-Elmer Spectrum GX FT-IR System instrument, in the region of $4000-400 \mathrm{~cm}^{-1}$, with 16 scans for each sample. The spectra were obtained by transmittance in a $\mathrm{KBr}$ pellet. Elemental analyses were performed in a CHN Perkin-Elmer equipment. Raman spectra were obtained in a Senterra Bruker equipment, with excitation wavelength of $633 \mathrm{~nm}$, a laser spot size of $20 \mu \mathrm{m}$ with confocal imaging microscope, power of $2 \mathrm{~mW}$ and 30 scans with $2 \mathrm{~s}$ each at 10 different spots. Powder $\mathrm{X}$-ray diffraction (XRD) data were obtained in a Rigaku equipment model Geigerflex using $\mathrm{Cu} K \alpha$ radiation, scanning from 10 to $80^{\circ}(2 \theta)$ at a scan rate of $4^{\circ} \mathrm{min}^{-1}$. The surface area was determined by nitrogen adsorption using the BET method with $\mathrm{N}_{2}$ adsorption/desorption in a LMAsorp instrument, with degassing at $250{ }^{\circ} \mathrm{C}$ for $4 \mathrm{~h}$ before the analysis. Scanning electron microscopy (SEM) analysis was done using a Quanta 200 FEG equipment. Zeta potential measurements were performed for each sample in a $\mathrm{pH}$ range from 2 to 12 in a Zetasizer Nano Series, Malvern Instruments.

\subsection{Preliminary studies on surface using probe dyes molecules}

$10 \mathrm{mg}$ of each material were added to $10 \mathrm{~mL}$ of an aqueous solution of methylene blue $25 \mathrm{ppm}$ (pH 6) and left to stand for $24 \mathrm{~h}$. The same procedure was performed using an aqueous solution containing $25 \mathrm{ppm}$ of indigo carmine. After $24 \mathrm{~h}$, methylene blue and indigo carmine concentrations were determined using an UV-Vis spectrometer model UV mini-1240 from Shimadzu, at wavelengths of 570 and $611 \mathrm{~nm}$, respectively. The tests were performed in triplicate.

\subsection{Preliminary studies on reactions of sulfide oxidation}

The kinetic studies of sulfide oxidation were performed with $20 \mathrm{mg}$ of materials suspended in $6 \mathrm{~mL}$ of a solution of $\mathrm{Na}_{2} \mathrm{~S} \cdot 9 \mathrm{H}_{2} \mathrm{O}\left(8 \mathrm{~g} \mathrm{~L}^{-1}, \mathrm{pH}\right.$ 10) in a Falcon tube. The suspensions were manually shaken for $30 \mathrm{~s}$ and centrifuged for one minute at $2400 \mathrm{rpm}$. The supernatant was removed and introduced in a quartz cuvette. Based on Lemos et al. (2012), kinetic studies were carried out monitoring the reaction at the wavelength $277 \mathrm{~nm}$ for the species $\mathrm{S}_{2}{ }^{2-}$. After each measurement, the supernatant was put back to the tube, manually shaken, centrifuged and introduced in the cuvette. This procedure was repeated until it completed $40 \mathrm{~min}$. Measures of electronic absorption UV-Vis were obtained using a Shimadzu UV 2550 spectrometer, interfaced with a microcomputer.

\section{Results and discussion}

The biochar used in this work was obtained from the pyrolysis of a mixture of sawdust and sugarcane straw, which are two important wastes in different areas Brazil. Biochar was pre-treated with concentrated $\mathrm{HCl}$ in order to remove soluble metals and other inorganic contaminants. EDS spectra performed of biochar before and after acid treatment suggest that several elements such as $\mathrm{Al}, \mathrm{P}, \mathrm{Ti}, \mathrm{K}, \mathrm{Ca}$, and $\mathrm{Fe}$ were leached from biochar.

TG analysis of biochar in $\mathrm{N}_{2}$ atmosphere after acid leaching showed an initial weight loss of ca. $5 \%$ due to adsorbed water, followed by a continuous gradual weight loss of near $50 \%$ likely related to the decomposition of organic structures present in biochar and also to the loss of surface/structural groups. Based on this result, biochar was treated at 400,600 and $800{ }^{\circ} \mathrm{C}$ for $1 \mathrm{~h}$ under $\mathrm{N}_{2}$ atmosphere and the samples named hereon as $\mathrm{B} 400, \mathrm{~B} 600$ and $\mathrm{B} 800$, respectively.

TG-MS analyses of the different biochars were obtained monitoring $m / z$ signals $18\left(\mathrm{H}_{2} \mathrm{O}\right)$ and $44\left(\mathrm{CO}_{2}\right)$ (Supplementary material). It was observed from the $\mathrm{m} / \mathrm{z} 18$ signal for the original biochar a loss near $100{ }^{\circ} \mathrm{C}$ related to adsorbed water molecules. In the range of $300-500{ }^{\circ} \mathrm{C}$, a broad peak was observed, likely related to the decomposition of different organic complex molecules present/impregnated in carbon and also more acidic surface groups such as carboxylic, $\mathrm{COOH}$ (Ando et al., 1991). From temperatures higher than $550{ }^{\circ} \mathrm{C}$, likely more stable surface or structural oxygen and hydrogen containing groups, e.g. $\mathrm{C}-\mathrm{H}$ and phenols, are decomposed (Ando et al., 1991; Kim et al., 2011; Mukherjee et al., 2011). In the case of sample B400, most of $m / z 18$ signal between 300 and $500{ }^{\circ} \mathrm{C}$ disappeared. This can indicate that the pretreatment at $400{ }^{\circ} \mathrm{C}$ led to the decomposition of most of the more reactive groups. However, an important peak centered near $600{ }^{\circ} \mathrm{C}$ was observed, suggesting the presence of a relatively high amount of $\mathrm{H}$ and $\mathrm{O}$ containing groups. As biochar is pretreated at 600 and $800{ }^{\circ} \mathrm{C}, \mathrm{B} 600$ and $\mathrm{B} 800$, all of the more reactive group were lost and only small amount of more stable groups remains in the materials. These results suggest that the thermal treatment at different temperatures gradually eliminates oxygen functionalities present in biochar.

TG-MS profiles for $m / z 44$ (related to $\mathrm{CO}_{2}$ ) showed similar results to $m / z 18$ signal profiles (Supplementary material). The decomposition of organics and surface oxygen functionalities to $\mathrm{CO}_{2}$ was observed in a wide temperature range, mainly $200-700^{\circ} \mathrm{C}$. As biochar is pretreated at 400,600 and $800{ }^{\circ} \mathrm{C}$, the formation of $\mathrm{CO}_{2}$ gradually decreases, indicating a gradual loss of oxygen with the treatment temperature.

TG-MS analyses also showed well defined peaks near $100{ }^{\circ} \mathrm{C}$ for both $\mathrm{m} / \mathrm{z}$ signals $18\left(\mathrm{H}_{2} \mathrm{O}\right)$ and $44\left(\mathrm{CO}_{2}\right)$. As these samples were exposed to air after thermal treatment, these peaks should be related to adsorbed $\mathrm{H}_{2} \mathrm{O}$ and $\mathrm{CO}_{2}$ molecules. The intensities of these peaks strongly increased as biochar was pre-treated at 400 and $600{ }^{\circ} \mathrm{C}$. On the other hand, the treatment at $800{ }^{\circ} \mathrm{C}$ led to a decrease on the adsorbed $\mathrm{H}_{2} \mathrm{O}$ and $\mathrm{CO}_{2}$. Calculations from integrated MS signals and from TG loss suggest that biochars B, B400, B600 and B800 adsorbed 3.1, 5.5, 5.3 and $1.1 \mathrm{mmol}_{\mathrm{H} 2 \mathrm{O}} \mathrm{g}^{-1}$, respectively. These carbons also adsorbed 0.13 , $0.12,0.71$ and $0.03 \mathrm{mmol}_{\mathrm{CO} 2} \mathrm{~g}^{-1}$, respectively. These results clearly indicate that thermal treatment strongly affects the adsorption capacity of the carbon. Improved adsorptions observed at 400 and $600{ }^{\circ} \mathrm{C}$ are likely related to the development of surface area/pore structure combined with the presence of oxygen surface groups and defective edges (Asai et al., 2011) which interact with $\mathrm{H}_{2} \mathrm{O}$ and $\mathrm{CO}_{2}$ molecules. Upon treatment at $800{ }^{\circ} \mathrm{C}$ the surface area is further improved but the adsorption of $\mathrm{H}_{2} \mathrm{O}$ and $\mathrm{CO}_{2}$ is decreased. This is likely related to the loss of oxygen functionalities which are apparently important for the adsorption of these molecules.

In fact, elemental analyses of the different samples (Fig. 1) 


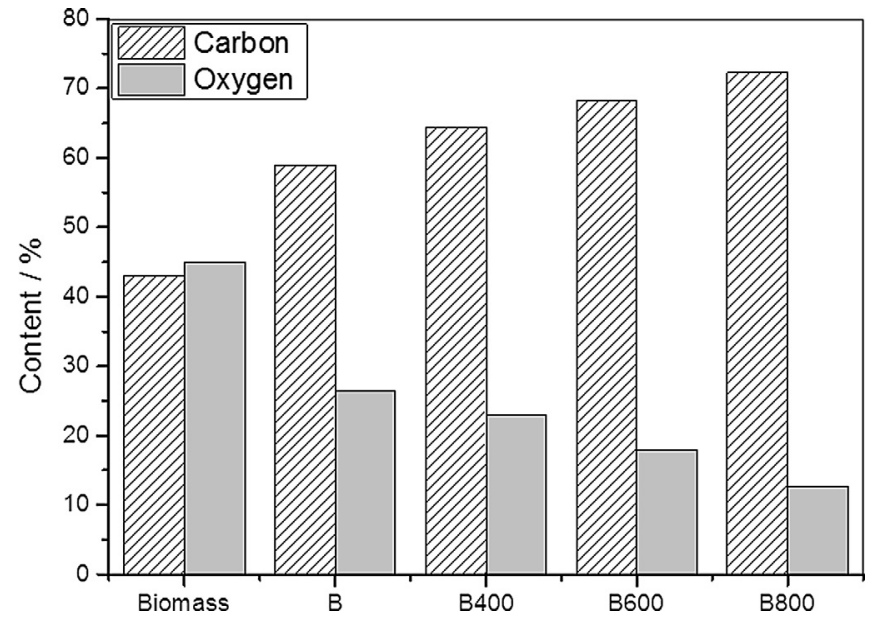

Fig. 1. Carbon and oxygen contents (\%) obtained by elemental analysis for the different samples.

suggested that oxygen content, $\mathrm{O} / \%$, decreased from approximately $45 \%$ (original biomass) down to $13 \%$ for $\mathrm{B} 800$, indicating a strong deoxygenation process. The gradual decrease in $\mathrm{H} / \%$ from 2.9 for $\mathrm{B}$ to $1.4 \%$ for $\mathrm{B} 800$ suggests the formation and loss of $\mathrm{H}_{2} \mathrm{O}$ molecules. On the other hand, the carbon content increased from 43 up to $72 \%$.

XRD patterns obtained for the materials B, B400, B600 and B800 showed a very broad and low intensity peak at approximately $25^{\circ}$ related to amorphous carbon containing poorly crystalized graphitic structures (Okolo et al., 2015).

IR spectra were recorded for $B$ and the materials produced after thermal treatment (see Supplementary material). It was observed for B a relatively intense and complex band in the range $1800-800 \mathrm{~cm}^{-1}$. Deconvolution results showed that thermal treatment at $400{ }^{\circ} \mathrm{C}$ strongly decreased the intensity of several bands, e.g. near $1700 \mathrm{~cm}^{-1}$, related to $\mathrm{C}=\mathrm{O}$ in carboxylic acids, ketones or aldehydes (Nanda et al., 2014), $1250 \mathrm{~cm}^{-1}$ possibly related to aromatic $\mathrm{C}-\mathrm{H}$ stretching (Yin et al., 2013), and $1060 \mathrm{~cm}^{-1}$ due to aliphatic $\mathrm{C}-\mathrm{O}$ stretching (Yin et al., 2013). This result suggests a strong deoxygenation process during thermal treatment, probably due to the decomposition of complex organic molecules and functional groups present in biochar. Bands at $1600 \mathrm{~cm}^{-1}$ likely related to $\mathrm{C}=\mathrm{C}$, around $1440 \mathrm{~cm}^{-1}$ due to $\mathrm{CH}_{2}$ and $\mathrm{C}-\mathrm{C}$ stretching centered in $1154 \mathrm{~cm}^{-1}$ (Arjunan \& Mohan, 2009) are still present in the sample B400. However, upon treatment at 600 and $800{ }^{\circ} \mathrm{C}$ these bands also strongly decreased. Similar results were observed by Luo et al. (2015) and were discussed in terms of decomposition of polar oxygenated functional groups in biochars to produce aromatic structures.

Raman spectra (Fig. 2) for all samples showed two typical carbon bands: D band between 1300 and $1400 \mathrm{~cm}^{-1}$ (related to the presence of defects in carbon structure) and G band between 1500 and $1600 \mathrm{~cm}^{-1}$ (related to more orbanized less defective graphene structures) (Keown et al., 2007). $I_{D} / I_{G}$ ratios calculated from $D$ and $G$ bands showed a gradual increase from 0.75 for $B$ to $1.00,1.29$ and 1.34 for samples $\mathrm{B} 400, \mathrm{~B} 600$ and B800, respectively. These data indicate that the ratio of disordered/ordered graphene structures increased. Probably, these more disordered defective graphene structures were formed by the decomposition of amorphous organic structures (invisible to Raman) during thermal treatments.

In order to estimate the dimensions of graphene structures present in carbon, a more detailed analysis of Raman spectra fitted according to the protocol detailed by Ribeiro-Soares et al. (2015) was carried out using four component peaks: two Lorentzians $\left(D^{A}\right.$ and $G^{A}$ peaks) and other two Gaussians ( $\mathrm{D}^{S}$ and $\mathrm{G}^{S}$ peaks). $\mathrm{D}^{S}$ and $\mathrm{G}^{S}$ peaks introduced in this fitting come from highly disordered areas and are important to be considered specially when the sample presents small crystallite sizes

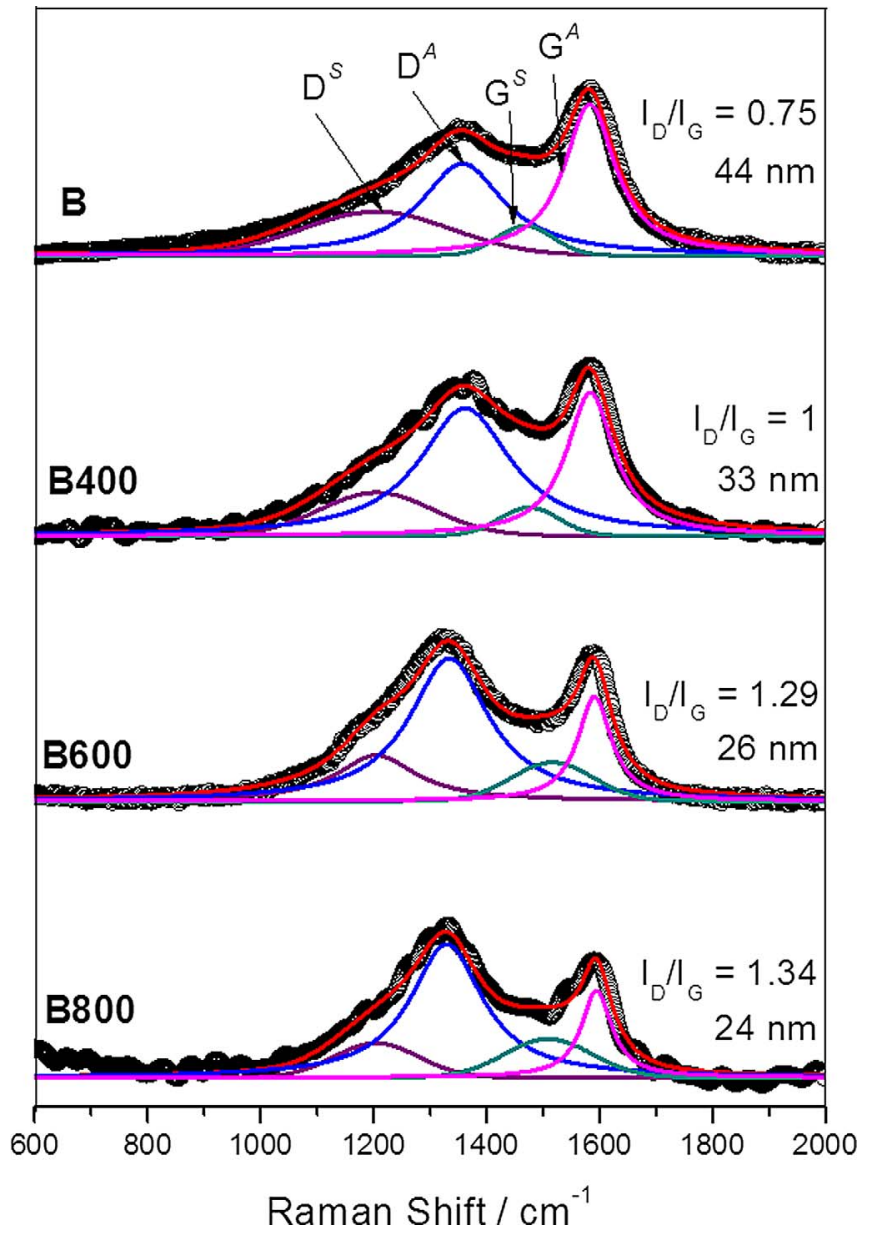

Fig. 2. Raman spectra of the biochar samples with $I_{D} / I_{G}$ ratios and estimated $L_{a}$ values.

(Ribeiro-Soares et al., 2015) (Fig. 2).

Surprisingly, the obtained average graphene structure sizes decreased from 44 to 33,26 and $24 \mathrm{~nm}$ with higher treatment temperatures. This decrease in graphene structure size can be discussed in terms of the formation of a large amount of new defective small graphene structures from thermal decomposition of amorphous organic matter (Eq. (1)).

Organic matter $_{\text {Amorphous }} \rightarrow$ Small defective graphene structures

$$
+\mathrm{CO}_{2} / \mathrm{H}_{2} \mathrm{O}
$$

Table 1 shows BET surface areas and volume of micro and mesopores obtained for biochar treated at different temperatures.

Surface area of materials strongly increased at higher temperatures of treatment, reaching values of $590 \mathrm{~m}^{2} \mathrm{~g}^{-1}$, mainly due to the creation of micropores. The increase observed in surface area is likely related to the decomposition of amorphous organic content within carbon structure leading to the formation of pores composed of walls based on defective aromatic structures. The temperature used to produce biochar during pyrolysis can also affect the surface area as demonstrated by

Table 1

Surface areas and micro and mesopores volumes obtained for B and thermally modified biochars.

\begin{tabular}{llll}
\hline Sample & \multicolumn{1}{c}{ BET surface area $/ \mathrm{m}^{2} \mathrm{~g}^{-1}$} & $\mathrm{~V}_{\text {micro }} / \mathrm{cm}^{3} \mathrm{~g}^{-1}$ & $\mathrm{~V}_{\text {meso }} / \mathrm{cm}^{3} \mathrm{~g}^{-1}$ \\
\hline B & $3.0 \pm 0.1$ & 0.0001 & 0.0069 \\
B400 & $30.0 \pm 0.7$ & 0.016 & 0.012 \\
B600 & $408 \pm 11$ & $0.163(91 \%)$ & $0.015(9 \%)$ \\
B800 & $590 \pm 14$ & $0.231(86 \%)$ & $0.038(14 \%)$ \\
\hline
\end{tabular}




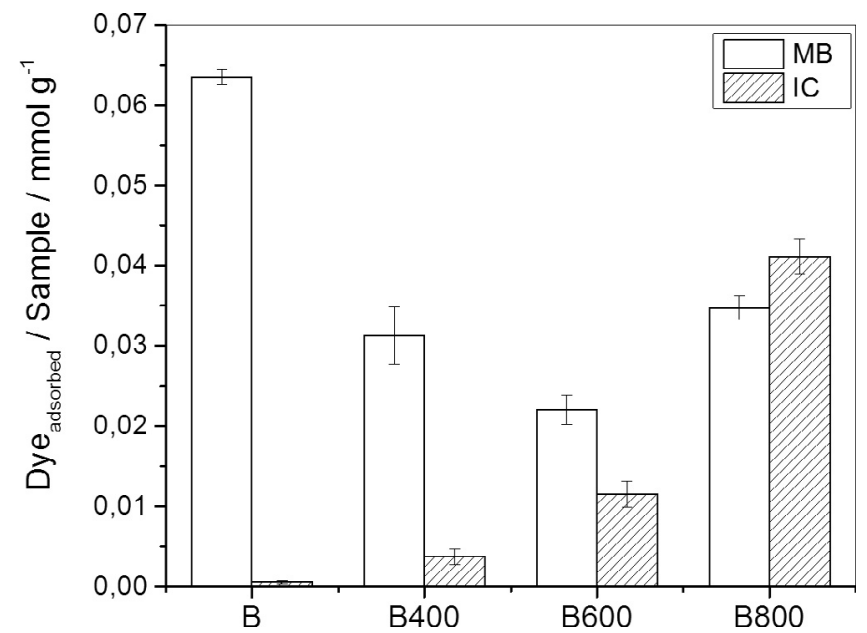

Fig. 3. Methylene blue (MB) and indigo carmine (IC) adsorption on biochar treated at different temperatures.

\section{Trigo et al. (2016).}

SEM images for the biochar sample showed the presence of folded and distorted sheet like structures presenting surface with some roughness (see Supplementary material). It is interesting to observe that the treatment at 400,600 and $800{ }^{\circ} \mathrm{C}$ did not cause a significant modification of the carbon texture. This result indicates that the decomposition observed is mainly of amorphous organic zones and that the main carbon structure was not significantly affected.

Zeta potential measurements strongly increased from $1.6 \mathrm{mV}$ for B400 to 2.5 and $4.4 \mathrm{mV}$ for the samples B600 and B800, respectively. Zeta potential measurement of the original biochar was not possible due to the solubilization of organic matter in aqueous solution. These results indicate that the sample B400 shows acidic groups responsible for the negative surface charges present on the carbon. As treatment temperature increased, these more acidic groups decomposed leading to an increase of the Zeta potential.

\subsection{Surface studies using probe dyes molecules}

Preliminary adsorption studies were performed using model dyes cationic methylene blue (MB) and anionic indigo carmine (IC) (Fig. 3). These dyes molecules can be used as models of industrial textile wastewater contaminants and also as probe species to investigate the effect of carbon surface charges and electrostatic effects during adsorption.

It was observed, generally, a decrease in the capacity of MB adsorption as the temperature of treatment of biochar increased. This behavior can be related to the decomposition of oxygenated groups on the biochar surface at higher temperatures (Li et al., 2016). As these oxygenated groups are in general negatively charged, e.g. carboxylates $-\mathrm{COO}_{\text {surf, }}^{-}$phenolates $-\mathrm{O}_{\text {surf, }}^{-}$the interaction between biochar and cationic dye MB significantly reduced. On the other hand, at $800{ }^{\circ} \mathrm{C}$ the adsorption of MB slightly increased likely due to strong increase on the surface area and porosity. For anionic dye IC, the observed behavior is the opposite. The loss of oxygenated groups led to an increase the interaction between material and dye, and this one is greatly adsorbed by B800.

\subsection{Reactions of sulfide oxidation}

The oxidation of aqueous sulfide promoted by activated carbons and other catalysts has been previously studied (Duan et al., 2007; Lemos et al., 2012). The mechanism of oxidation is not totally cleared yet, but it possibly involves the interaction of aqueous $\mathrm{S}^{2-}$ with the redox oxygen surface groups, forming a sulfur intermediate oxidized species. The sulfur oxidized species can then react with another $\mathrm{S}^{2-}$ producing

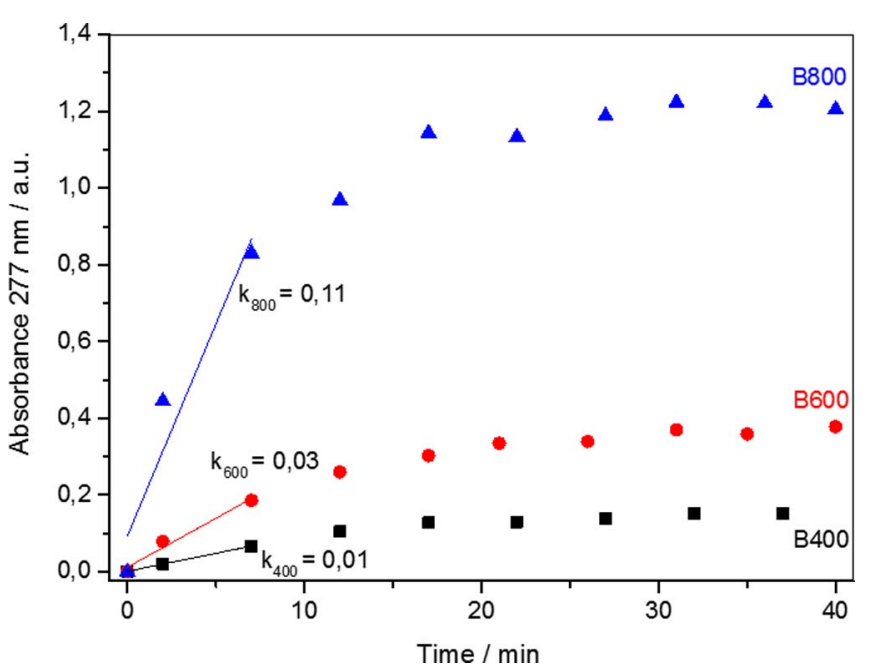

Fig. 4. Kinetic profiles of sulfide oxidation for the materials, monitored for the absorbance at $280 \mathrm{~nm}$ related to the production of the species $\mathrm{S}_{2}{ }^{2-}$, with respective rate constants $\mathrm{k}$.

disulfides or polysulfides (Eq. (2)).

$2 \mathrm{~S}^{2-}-2 \mathrm{e}^{-} \rightarrow 2 \mathrm{~S}^{-} \rightarrow \mathrm{S}_{2}^{2-}$

The electrons involved in the reaction can be received by the carbon structure and transferred to the reaction medium.

The materials produced in this work were tested in reactions of sulfide oxidation. The reaction kinetics for B800 was performed monitoring the evolution of the UV absorption at $277 \mathrm{~nm}$, related to the species $\mathrm{S}_{2}{ }^{2-}$ (Linkous et al., 2004), used to evaluate the catalytic efficiency of the materials. Absorption bands around 315 and $375 \mathrm{~nm}$ were also observed, related to the formation of $\mathrm{S}_{3}{ }^{2-}$ (Steudel et al., 1989).

Fig. 4 shows kinetic curves resulting from measurements of absorbance at $277 \mathrm{~nm}$ of the solution over time for the different materials studied. The sample B was initially tested in this reaction but it showed a significant release of colored organic contamination to the solution which strongly interfered in the reaction and spectroscopic measurements.

It can be observed that $\mathrm{B} 800$ presented the best performance for sulfide oxidation with an initial pseudo-zero order rate constant $0.11 \mathrm{~min}^{-1}$ compared to 0.03 and $0.01 \mathrm{mn}^{-1}$. The discussion of these results should take into account the different physico-chemical characteristics of the carbon, such as surface area and the nature and concentration of oxygen surface groups. Surface area and pore structure should play an important role for sulfide oxidation over these materials (Lemos et al., 2012). On the other hand, the presence of redox oxygen surface groups is also critical for the catalytic activity for sulfide oxidation (Lemos et al., 2012). Carboxylic groups are not active for sulfide oxidation and should have a negative effect due to the repulsion between surface negative charges $\left(-\mathrm{COO}^{-}\right)$and the $\mathrm{S}^{2-}$ or $\mathrm{HS}^{-}$adsorbates. On the other hand, the presence of more redox basic groups such as quinones has been described as responsible for the activity for sulfide oxidation. Therefore, the high sulfide oxidation activity for the sample B800 is likely related to the presence of some redox oxygen functionalities coupled with graphene structures. It is also interesting to analyze the sulfide oxidation activity normalized by the surface area (see Supplementary Material). The obtained results showed that the most active material considering $\mathrm{m}^{2}$ is $\mathrm{B} 400$ followed by $\mathrm{B} 800$ and $\mathrm{B} 600$. This result is likely due to the presence of higher concentrations of the redox oxygen surface groups, especially quinones and hydroquinones, active for sulfide oxidation. These groups show good stability up to $400{ }^{\circ} \mathrm{C}$ but decompose at temperatures near $600^{\circ} \mathrm{C}$ ( $\mathrm{Li}$ et al., 2017).

In summary, biochar contains a large concentration of an organic 
complex amorphous phase (ca. $50 \mathrm{wt} \%$ ) which is impregnated/mixed with the initial carbon structure. As the biochar is thermally treated, these organic structures decompose/pyrolyze to produce $\mathrm{CO}_{2} / \mathrm{H}_{2} \mathrm{O}$ and more carbon structures. As suggested by Raman spectroscopy, these carbon structures are likely based on defective graphene with dimensions of ca. 24-33 nm with an increase of the microporous surface area from 3 to $590 \mathrm{~m}^{2} \mathrm{~g}^{-1}$. The formation of these graphene nanoparticles might be correlated with the relatively high $\mathrm{CO}_{2}$ and $\mathrm{H}_{2} \mathrm{O}$ adsorption observed for the samples B400 and B600. According to the work of Asai et al. (2011), large concentration of edges and defects present in carbon nanostructures are responsible for the strong adsorption of both molecules, $\mathrm{CO}_{2}$ and $\mathrm{H}_{2} \mathrm{O}$.

Thermal decomposition leads to a decrease on the oxygen content of biochar from $27 \%$ to ca. $14 \%$ at $800{ }^{\circ} \mathrm{C}$. At $800{ }^{\circ} \mathrm{C}$ only very stable oxygen surface groups are present, likely related to ether and ketone/ quinone functionalities. Combined with the high surface area and lower negative surface charges, these redox groups are likely responsible for the good activity observed for sulfide oxidation. A general idea of these physico-chemical modifications of biochar upon thermal treatment is given in Supplementary Material.

\section{Conclusions}

Thermal treatment can be used to tune different surface properties of biochar such as surface area/porosity, oxygen functionalities and reactivity. Treatments at 400,600 and $800{ }^{\circ} \mathrm{C}$ lead to the decomposition of organic complex phases present in biochar with the development of micropores likely formed by nanometric graphene structures and a gradual decrease on oxygen concentration due to the decomposition of oxygen surface functionalities. As a result, surface properties such as adsorption and reactivity strongly changed. These promising results indicate that a simple thermal treatment can be used to produce specific carbon materials for different applications adsorption and catalysis.

\section{Acknowledgements}

Authors thank the financial support of Projeto Iara (FUNTEC BNDES), Pró-Reitoria de Pesquisa - Universidade Federal de Minas Gerais, FAPEMIG, CNPq, Fundep and Capes. To UFMG Microscopy Center for providing equipment and technical support for the experiments involving electronic microscopy. To Jardim, E. O. for BET analyses.

\section{Appendix A. Supplementary data}

Supplementary data associated with this article can be found, in the online version, at http://dx.doi.org/10.1016/j.biortech.2017.07.099.

\section{References}

Ahmed, M.B., Zhou, J.L., Ngo, H.H., Guo, W., 2016. Insight into biochar properties and its cost analysis. Biomass Bioenergy 84, 76-86.

Ando, T., Fujimoto, Y., Morisaki, S., 1991. Analysis of differential scanning calorimetric data for reactive chemicals. J. Hazard. Mater. 28 (3), 251-280.

Arjunan, V., Mohan, S., 2009. Fourier transform infrared and FT-Raman spectra, assignment, ab initio, DFT and normal co-ordinate analysis of 2-chloro-4-methylaniline and 2-chloro-6-methylaniline. Spectrochim. Acta A 72 (2), 436-444.

Asai, M., Ohba, T., Iwanaga, T., Kanoh, H., Endo, M., Campos-Delgado, J., Terrones, M., Nakai, K., Kaneko, K., 2011. Marked adsorption irreversibility of graphitic nanoribbons for CO2 and H2O. J. Am. Chem. Soc. 133 (38), 14880-14883.

Beesley, L., Moreno-Jimenez, E., Gomez-Eyles, J.L., Harris, E., Robinson, B., Sizmur, T., 2011. A review of biochars' potential role in the remediation, revegetation and restoration of contaminated soils. Environ. Pollut. 159 (12), 3269-3282.

Ben Hariz, I., Al Ayni, F., Monser, L., 2014. Removal of sulfur compounds from petroleum refinery wastewater through adsorption on modified activated carbon. Water Sci. Technol. 70 (8), 1376-1382.

Brennan, A., Moreno Jimenez, E., Alburquerque, J.A., Knapp, C.W., Switzer, C., 2014. Effects of biochar and activated carbon amendment on maize growth and the uptake and measured availability of polycyclic aromatic hydrocarbons (PAHs) and potentially toxic elements (PTEs). Environ. Pollut. 193, 79-87.
Bridgwater, A.V., 2012. Review of fast pyrolysis of biomass and product upgrading. Biomass Bioenergy 38, 68-94.

Burgess, J.E., Parsons, S.A., Stuetz, R.M., 2001. Developments in odour control and waste gas treatment biotechnology: a review. Biotechnol. Adv. 19 (1), 35-63.

Chintala, R., Schumacher, T.E., Kumar, S., Malo, D.D., Rice, J.A., Bleakley, B., Chilom, G., Clay, D.E., Julson, J.L., Papiernik, S.K., Gu, Z.R., 2014. Molecular characterization of biochars and their influence on microbiological properties of soil. J. Hazard. Mater. $279,244-256$.

Cunha, I.T., Teixeira, I.F., Albuquerque, A.S., Ardisson, J.D., Macedo, W.A.A., Oliveira, H.S., Tristão, J.C., Sapag, K., Lago, R.M., 2016a. Catalytic oxidation of aqueous sulfide in the presence of ferrites (MFe2O4, $\mathrm{M}=\mathrm{Fe}, \mathrm{Cu}, \mathrm{Co}$ ). Catal. Today 259, Part 1 , 222-227.

Cunha, I.T., Teixeira, I.F., Mesquita, J.P., Ardisson, J.D., Binatti, I., Pereira, F.V., Lago, R.M., 2016b. Cellulose nanocrystals assembled on the $\mathrm{Fe}_{3} \mathrm{O}_{4}$ surface as precursor to prepare interfaced $\mathrm{C} / \mathrm{Fe}_{3} \mathrm{O}_{4}$ composites for the oxidation of aqueous sulfide. J. Braz. Chem. Soc. 27, 363-371.

Dilgin, Y., Kızılkaya, B., Ertek, B., Işık, F., Dilgin, D.G., 2012. Electrocatalytic oxidation of sulphide using a pencil graphite electrode modified with hematoxylin. Sensor. Actuat. B-Chem. 171-172, 223-229.

Ding, Y., Liu, Y., Liu, S., Li, Z., Tan, X., Huang, X., Zeng, G., Zhou, Y., Zheng, B., Cai, X., 2016. Competitive removal of $\mathrm{Cd}(\mathrm{ii})$ and $\mathrm{Pb}$ (ii) by biochars produced from water hyacinths: performance and mechanism. RSC Adv. 6 (7), 5223-5232.

Duan, H., Yan, R., Koe, L.C.C., Wang, X., 2007. Combined effect of adsorption and biodegradation of biological activated carbon on $\mathrm{H}_{2} \mathrm{~S}$ biotrickling filtration. Chemosphere 66 (9), 1684-1691.

Huang, D., Wang, Y., Zhang, C., Zeng, G., Lai, C., Wan, J., Qin, L., Zeng, Y., 2016. Influence of morphological and chemical features of biochar on hydrogen peroxide activation: implications on sulfamethazine degradation. RSC Adv. 6 (77), 73186-73196.

Jin, H., Hanif, M.U., Capareda, S., Chang, Z., Huang, H., Ai, Y., 2016. Copper(II) removal potential from aqueous solution by pyrolysis biochar derived from anaerobically digested algae-dairy-manure and effect of $\mathrm{KOH}$ activation. J. Environ. Chem. Eng. 4 (1), 365-372.

Keown, D.M., Li, X., Hayashi, J.-I., Li, C.-Z., 2007. Characterization of the structural features of char from the pyrolysis of cane trash using Fourier transform - Raman spectroscopy. Energy Fuel 21 (3), 1816-1821.

Kim, P., Hensley, D., Labbe, N., 2014. Nutrient release from switchgrass-derived biochar pellets embedded with fertilizers. Geoderma 232, 341-351.

Kim, P., Johnson, A., Edmunds, C.W., Radosevich, M., Vogt, F., Rials, T.G., Labbé, N., 2011. Surface functionality and carbon structures in lignocellulosic-derived biochars produced by fast pyrolysis. Energy Fuel 25 (10), 4693-4703.

Lee, J.W., Kidder, M., Evans, B.R., Paik, S., Buchanan Iii, A.C., Garten, C.T., Brown, R.C., 2010. Characterization of biochars produced from cornstovers for soil amendment. Environ. Sci. Technol. 44 (20), 7970-7974.

Lemos, B.R.S., Teixeira, I.F., De Mesquita, J.P., Ribeiro, R.R., Donnici, C.L., Lago, R.M., 2012. Use of modified activated carbon for the oxidation of aqueous sulfide. Carbon 50 (3), 1386-1393.

Lemos, B.R.S., Teixeira, I.F., Machado, B.F., Alves, M.R.A., de Mesquita, J.P., Ribeiro, R.R., Bacsa, R.R., Serp, P., Lago, R.M., 2013. Oxidized few layer graphene and graphite as metal-free catalysts for aqueous sulfide oxidation. J. Mater. Chem. A 1 (33), 9491-9497.

Li, G., Zhu, W., Zhang, C., Zhang, S., Liu, L., Zhu, L., Zhao, W., 2016. Effect of a magnetic field on the adsorptive removal of methylene blue onto wheat straw biochar. Bioresour. Technol. 206, 16-22.

Li, H., Dong, X., da Silva, E.B., de Oliveira, L.M., Chen, Y., Ma, L.Q., 2017. Mechanisms of metal sorption by biochars: biochar characteristics and modifications. Chemosphere $178,466-478$.

Li, X., Shen, Q., Zhang, D., Mei, X., Ran, W., Xu, Y., Yu, G., 2013. Functional groups determine biochar properties ( $\mathrm{pH}$ and EC) as studied by two-dimensional ${ }^{13} \mathrm{C}$ NMR correlation spectroscopy. PLoS ONE 8 (6), e65949.

Linkous, C.A., Huang, C.P., Fowler, J.R., 2004. UV photochemical oxidation of aqueous sodium sulfide to produce hydrogen and sulfur. J. Photochem. Photobiol. A-Chem. 168 (3), 153-160.

Liu, P., Ptacek, C.J., Blowes, D.W., Landis, R.C., 2016. Mechanisms of mercury removal by biochars produced from different feedstocks determined using X-ray absorption spectroscopy. J. Hazard. Mater. 308, 233-242.

Luo, L., Xu, C., Chen, Z., Zhang, S., 2015. Properties of biomass-derived biochars: combined effects of operating conditions and biomass types. Bioresour. Technol. 192, 83-89.

Mukherjee, A., Zimmerman, A.R., Harris, W., 2011. Surface chemistry variations among a series of laboratory-produced biochars. Geoderma 163 (3-4), 247-255.

Nanda, S., Azargohar, R., Kozinski, J.A., Dalai, A.K., 2014. Characteristic studies on the pyrolysis products from Hydrolyzed Canadian Lignocellulosic Feedstocks. Bioenergy Res. 7 (1), 174-191.

Okolo, G.N., Neomagus, H.W.J.P., Everson, R.C., Roberts, M.J., Bunt, J.R., Sakurovs, R., Mathews, J.P., 2015. Chemical-structural properties of South African bituminous coals: insights from wide angle XRD-carbon fraction analysis, ATR-FTIR, solid state 13C NMR, and HRTEM techniques. Fuel 158, 779-792.

Qian, L., Zhang, W., Yan, J., Han, L., Gao, W., Liu, R., Chen, M., 2016. Effective removal of heavy metal by biochar colloids under different pyrolysis temperatures. Bioresour. Technol. 206, 217-224.

Ribeiro-Soares, J., Oliveros, M.E., Garin, C., David, M.V., Martins, L.G.P., Almeida, C.A., Martins-Ferreira, E.H., Takai, K., Enoki, T., Magalhães-Paniago, R., Malachias, A., Jorio, A., Archanjo, B.S., Achete, C.A., Cançado, L.G., 2015. Structural analysis of polycrystalline graphene systems by Raman spectroscopy. Carbon 95, 646-652.

Schmidt, H.-P., Kammann, C., Niggli, C., Evangelou, M.W.H., Mackie, K.A., Abiven, S., 
2014. Biochar and biochar-compost as soil amendments to a vineyard soil: Influences on plant growth, nutrient uptake, plant health and grape quality. Agric. Ecosyst. Environ. 191, 117-123.

Shan, D., Deng, S., Zhao, T., Wang, B., Wang, Y., Huang, J., Yu, G., Winglee, J., Wiesner, M.R., 2016. Preparation of ultrafine magnetic biochar and activated carbon for pharmaceutical adsorption and subsequent degradation by ball milling. J. Hazard. Mater. 305, 156-163.

Steudel, R., Holdt, G., Gobel, T., 1989. Ion-Pair chromatographic-separation of inorganic sulfur anions including polysulfide. J. Chromatogr. 475, 442-446.

Stutter, M.I., 2015. The composition, leaching, and sorption behavior of some alternative sources of phosphorus for soils. Ambio 44, S207-S216.

Takaya, C.A., Fletcher, L.A., Singh, S., Anyikude, K.U., Ross, A.B., 2016. Phosphate and ammonium sorption capacity of biochar and hydrochar from different wastes. Chemosphere 145, 518-527.

Tang, K., An, S., Nemati, M., 2010. Evaluation of autotrophic and heterotrophic processes in biofilm reactors used for removal of sulphide, nitrate and COD. Bioresour. Technol.
101 (21), 8109-8118.

Trigo, C., Cox, L., Spokas, K., 2016. Influence of pyrolysis temperature and hardwood species on resulting biochar properties and their effect on azimsulfuron sorption as compared to other sorbents. Sci. Total Environ. 266-567, 1454-1464.

Usman, A.R.A., Abduljabbar, A., Vithanage, M., Ok, Y.S., Ahmad, M., Ahmad, M., Elfaki, J., Abdulazeem, S.S., Al-Wabel, M.I., 2015. Biochar production from date palm waste: charring temperature induced changes in composition and surface chemistry. J. Anal. Appl. Pyrolysis 115, 392-400.

Yargicoglu, E.N., Sadasivam, B.Y., Reddy, K.R., Spokas, K., 2015. Physical and chemical characterization of waste wood derived biochars. Waste Manage. 36, 256-268.

Yin, R., Liu, R., Mei, Y., Fei, W., Sun, X., 2013. Characterization of bio-oil and bio-char obtained from sweet sorghum bagasse fast pyrolysis with fractional condensers. Fuel 112, 96-104.

Zhao, L., Cao, X., Zheng, W., Scott, J.W., Sharma, B.K., Chen, X., 2016 Copyrolysis of biomass with phosphate fertilizers to improve biochar carbon retention, slow nutrient release, and stabilize heavy metals in soil. ACS Sus. Chem. Eng. 4 (3), 1630-1636. 